\title{
Sustainable tourism development in the Masai Mara National Reserve, Kenya, East Africa
}

\author{
J. Onchwati, H. Sommerville \& N. Brockway \\ Hotel and Tourism Management Institute, Switzerland
}

\begin{abstract}
The Masai Mara Game Reserve is Kenya's finest wildlife reserve, one of the world's top tourist attractions and vital to Kenya's economy. Recently, concerns have been expressed about the sustainability of tourism given the threats of depletion of indigenous animals, degradation of the landscape and impact on the native Masai Mara tribespeople. The challenge now is to create a sustainable situation that protects the interests of all stakeholders. This paper explores the views of four key stakeholder groups: the Masai people; conservationists including the Kenya Wildlife Service and the Masai Mara Game Reserve management; local tourism and game lodge operators; and government departments. Interviews were carried out with representatives of each stakeholder group to gain insight into their needs from tourism and whether these needs are currently met; suggestions for short- and long-term tourism developments; and the economic implications of tourism in the Masai Mara. Interview data were supplemented by an extensive period of observation. The findings indicate that the growth of tourism and the lack of resources to manage tourism are leading to persistent tensions between stakeholders and presenting long-term threats to the tourism industry. Overpopulation, changes in land use, poaching, deforestation, land degradation, conflicts due to unequal sharing of revenue, poor infrastructure and insecurity all contribute to these tensions. All stakeholders agreed that urgent action is required and lessons must be learned in order to sustain tourism and ensure the Masai Mara is preserved for future generations.
\end{abstract}

Keywords: Masai Mara, stakeholder views, sustainable tourism, tourism development, tourism impact. 


\section{Introduction}

The Masai Mara Game Reserve in Kenya is named after the Masai people, the traditional inhabitants of south-western Kenya, and the Mara River, which runs through it. The Masai Mara covers an area of 1672 square kilometres and is famous for its exceptional population of game, its annual migration of wildebeest and because it offers a haven for many endangered species, including the African elephant and the black rhino. The Masai Mara is Kenya's finest wildlife reserve and one of the world's most important tourist attractions. The Masai Mara was established as a world heritage site in 1989 in a bid to protect the existing wildlife (Bhandari [2]).

The Masai Mara is also a major contributor to Kenya's economy and a major earner of foreign exchange (http://www.tourism.go.ke). Despite the worldwide decline in tourism, it is estimated that there are approximately 200,000 visitors per year to the Masai Mara. A peak number of 316,500 visitors was recorded in 2006 when Masai Mara Game Reserve entrance fees alone netted 5.5 million US dollars.

However, tourism also impacts on the local wildlife, on the local people and on the environment. The challenge now being faced is how to create a sustainable situation which protects the interests of tourists, the wildlife, the Masai traditional culture and the natural environment.

\section{Sustainable development}

Sustainable development is a much-used phrase in international circles, but it is a concept that still has no clear definition or clear time frame in terms of what constitutes a sustainable period. In 1987, the report of the Brundtland Commission offered the definition of sustainable development as development that meets the needs of the present without compromising the ability of future generations to meet their own needs' (Brundtland [1]:3). This definition can directly be applied to the situation in the Masai Mara where current economic, social, environmental and cultural factors are closely dependent on one another and will remain so even if needs change. Thus, sustainable development requires a balance between stakeholder needs and the key issue in balancing those needs lies in managing the inevitable tensions between them and addressing issues before irreparable damage is done.

Tensions between stakeholders may be economic, social, environmental or cultural and may arise between different stakeholders or between different individuals within stakeholder groups. Thus, some stakeholders may think sustainability is not an issue, others may think it is a government function to ensure sustainability, while others may even think sustainability is impossible to achieve. Thus while the stakeholders may be segmented by groups, they may also be segmented by attitudes and beliefs. 


\section{Stakeholders in the Masai Mara}

\subsection{The wildlife}

Arguably, the wildlife of the Masai Mara constitute the major group of stakeholders whose interests lie at the heart of this whole debate and for whom tourism development could prove catastrophic. As MacKillop ([5]:3) argues, 'wildlife is a peculiarly fragile resource, too much human handling and it can be gone forever'. However, the wildlife are unable to speak for themselves, hence management of this 'fragile resource' has been promoted by the creation of a wildlife reserve where poaching is forbidden and where income is generated by tourists being able to watch the animals in their natural environment. However, the preservation of wildlife is difficult to achieve. Said [8] points out that 10 out of the 13 wild ungulate species in Masai Mara declined in numbers during the last 25 years of the twentieth century and argued that these reductions were related to changes in land use rather than climate. MacKillop [5] argues in favour of planned land use and the avoidance of intensive land use, but acknowledges that tensions arise when large areas of land are put aside for relaxation and leisure activities when there are so many starving people in the world. Further tensions arise with regard to the preservations of predators, which may kill and injure many of the animals relied upon by the local indigenous human population for their food.

\subsection{The Masai Mara tribespeople}

There is tension between the development of tourism and the indigenous Masai Mara tribespeople. Many do make a good living from visiting the tourist lodges and camps, by performing traditional shows and/or selling local handicrafts, however there is an ever-present danger that they will be exploited and that they, along with their traditional culture and environment, will become 'commodities' to be manipulated by the tourist industry.

The Kenyan government issued a directive that local communities should be paid 19\% of all Game Reserve revenues (Walpole and Leader-Williams [11]). However, the terms of this directive have not been fulfilled which has led to widespread resentment and, in extreme cases, the protest action of killing wildlife.

There is also tension regarding land ownership (MacDonald and Azumi [4]). Many members of the Masai Tribe were displaced by the creation of the Game Reserve, resulting in a reduction in their communal land. MacDonald and Azumi argue for forging links between developers and local residents which acknowledge the need to promote local livelihoods together with the need to conserve wildlife and its habitat, in order to encourage the acceptance of the tourism developments which are taking place. There is a need for consultation, partnerships, consensus building and pro-active planning. Achieving a balance between the protection of the Masai culture and the development of tourism is critical to sustainability. 


\subsection{The tourism operators}

Since the opening of the first tourist lodge, Kekorok, in 1963, the Masai Mara has seen more than 50 lodges open. Over 30 offer high quality, high price accommodation and are developed beside animal watering holes and in other scenic locations. These developments raise issues for sustainability as the Masai community feels that the investors have interfered with their ancestral watering holes and obstructed access for their Masai livestock. Further, as Omondi [6] reported, much of the money generated by tourism goes towards luxury lodges, transport costs, and foreign package tour operators rather than to the Masai people. Omondi points out that less than $30 \%$ of employees in the lodges are locals. Omondi also raises the issue of the huge amount of waste materials produced by the tourist industry which need to be disposed of responsibly. However, at many levels the needs of the hotel lodge operators, tourists and locals are similar, as all will lose a great deal if tourism is sustained.

\subsection{The Kenyan government}

Tourism is a powerful tool for boosting economic development. Hence, the government in Kenya argues that the benefits of tourism far outweigh its problems. The explicit benefits in terms of revenue, employment and investment are supplemented by the spin-off benefits of, for example, foreign exchange inflow and aircraft landing fee revenues. Since employment opportunities and earnings have also increased due to the increase in the number of tourists, the government also benefits in terms of increased tax income.

In 2008, the post-election crisis in Kenya triggered a 90 per cent collapse in visitor numbers, which forced hotels to close and led to thousands of job cuts. However, recently the situation is beginning to stabilise and the return of tourists is anticipated. This situation presents the government with an opportunity to take action to improve sustainability. One suggestion is to curb the number of 'budget' visitors and concentrate on 'high yield' tourists, as Pflanz [7] reported,

"We have something unique to preserve in the Masai Mara, and we have got to get a bit snobbish about it. We are going to have to aim at a non-mass market approach for places like the Mara. Go for quality not quantity."

The Kenyan government has introduced a number of initiatives to help balance wildlife, people and tourism. For example, the Olderkessi/Naikarra Community-Conservation and Tourism Initiative has been set up to help establish community associations for wildlife conservation and natural resource management and the Kenya Tourism Trust Fund provides investment funds for the Masai Mara. The Ewaso Ngiro South Development Authority oversees spending these investments for the benefit of the environment while continuing to enhance tourism. However, there is a danger that short-term profit will be sought, rather than long-term sustainability.

Huby [3] highlights the need for government to look at building a local infrastructure to protect both the economy and the wildlife. The Kenyan 
government seeks to implement Agenda 21 (UNEP [10]) in the Masai Mara and surrounding areas where it is a generally held belief that the needs of the stakeholders are not balanced.

\subsection{Overview of stakeholder interests}

In summary, according to the Brundtland report [1], sustainable development requires meeting the basic needs of all, to achieve a balance of stakeholders' needs for the long term. In the case of the Masai Mara the wildlife needs safety, no poaching, an unspoiled ecological environment; the Masai people need to be satisfied that the tourism benefits them and that revenue due to them is paid; the tourist operators need to provide tourists with an unspoiled harmonious and peaceful atmosphere to relax and enjoy nature and high quality accommodation and a high level and sustainable tourism revenue; the Kenyan government needs to sustain the revenue from tourism to boost the country's economy. Thus, many stakeholders have a vested interest in maintaining the Masai Mara as an attractive tourist destination. This paper explores the needs of the various stakeholders in the Masai Mara in order to identify ways to achieve sustainable tourism in the region.

\section{Research methodology}

A qualitative grounded theory approach (Strauss and Corbin [9]) was adopted to explore the views of a range of stakeholders in the Masai Mara Game Reserve. The key stakeholder groups were identified as:

1. The wildlife, whose interests were represented by local and international conservationists (Respondents 1, 4, 7 and 8);

2. The Masai Mara tribespeople (Respondents 2, 3 and 6);

3. The tourism operators represented by game lodge operators (Respondents 5 and 10);

4. The Kenyan government (Respondent 9).

Ten semi-structured interviews were carried out with these stakeholder representatives. Where local tribespeople were involved, a village leader was also present at each interview in order to ensure full cooperation and to provide interpretation where required. Each interview lasted approximately 30 minutes, was audio recorded and subsequently transcribed.

Interviews concentrated on gaining insight into stakeholder views on their needs from tourism and whether or not these needs are currently met; suggestions for short- and long-term improvements in tourism; the historical and current reasons for conflict in the area and suggestions for the resolution of this conflict; and the economic implications of tourism in the Masai Mara. The interview data were supplemented by an extensive period of observation in the Game Reserve both prior to conducting the interviews and subsequently on field tours with some of the interviewees. 


\section{Findings and discussion}

\subsection{Wildlife}

All stakeholders agreed that wildlife in the Masai Mara is under threat and that urgent action is required to address wildlife issues:

We must continue having a strong protectionist policy towards wildlife. Otherwise, it will be too late for us to save the diminishing wildlife that make up the park (Respondent 1).

A number of factors were identified as contributing to this situation, including 'population growth', the 'shift towards a mixed economy' and 'conflict over the diminishing unfenced land between the wild animals and the Masai herdsmen'. In other words, due to recent dramatic rises in Kenya's population, there is increasing pressure to use the available land for crop production, rather than make it available for wildlife preservation.

Among many respondents there was an acute awareness of the issues facing the future of the Masai Mara:

The dilemma of weighing up the positive benefits of tourism in terms of wildlife conservation and economic benefit to communities with the potential erosion of cultural identity remains to be a constant issue (Respondent 1).

In addition, the Masai people are developing negative attitudes towards the wildlife and there are problems 'sharing the space' which wildlife need for their survival and the Masai people need to make a living. In the past, the Masai have taken actions into their own hands:

When the Masai pastoralists were thrown out of these grasslands, they also swiftly reacted by killing most of the black rhino as well as turning against the other wild animals (Respondent 3 ).

Further threats to wildlife are evident in an increase in activities such as 'poaching', the growth of 'unplanned trading centres' dealing in the 'bush meat trade' and 'the over-conversion of rangelands to livestock and agricultural production at the expense of wildlife'. For some stakeholders, these actions are the result of:

Ineffective controls and sustainability, and a lack of thorough examination of the environmental impacts of tourism and of environmental resource utilization (Respondent 10).

Some stakeholders attribute the failings in wildlife conservation to a lack of financial resources, institutional weaknesses of the wildlife conservation and management department and a lack of government support:

The decline is due to lack of proper management of wildlife outside the conservation areas by the concerned authorities, which I think needs more serious improvement (Respondent 8).

There was an open recognition of the need to adopt a coordinated approach in future actions

The way forward lies in integrating the wildlife management with conservation together with the local people (Respondent 1). 
Many stakeholders agreed that the rise in tourism and a failure to address issues of sustainability lie at the heart of the problems experienced:

Due to the existence of tourism practices, there have been serious consequences for the plants and animals species as well as the disruption of the grass cover caused by the game drives through the crisscrossing of motor vehicles in the park areas (Respondent 10).

In addition to the damage done by traffic 'wildlife is under severe threat due to the pollution which is caused by human refuse'.

In general, stakeholders are somewhat pessimistic about future prospects for the wildlife of the Masai Mara:

[If we] go head to head with baboons, zebra, gazelles and elephants eventually, I bet with you, it's a contest the animals will lose (Respondent 3).

From many perspectives, the key to conservation was perceived to lie in forging alliances between the Masai Mara people and the developers so that all are working in the best interests of the wildlife of the Reserve. The Reserve environment is undergoing rapid change and a number of important challenges remain to be addressed in order to avoid 'scenes of conflict between the Masai and conservationists'. Cooperation is essential and the Masai people must be encouraged to play a major role in conservation:

The Masais have lived with the wildlife for their entire history ... and the reserve's conservation will remain to be intimately tied to the Masai by how they utilize their land (respondent 2).

Conservationists view population growth as a 'depressing issue' as it places pressure on the available land and in turn leads to deforestation and shrinking areas where wildlife can thrive. Further pressure is placed on the land by the construction of lodges and hotels to accommodate the tourists and by the development of trading centres and markets and there is a general feeling that these issues 'must be addressed with seriousness and sense of urgency'.

All arguments ultimately returned to the theme of balancing conservation of the natural environment, wildlife and the Masai people with the tourist trade and there were frequent expressions of the importance of the government role in achieving a sustainable situation:

The government has a responsibility to come up with proper plans for proper control over the lands (Respondent 2).

\subsection{The Masai Mara tribespeople}

For centuries, the Masai Mara people have lived in harmony with wildlife and nature. It is only relatively recently that developments have required them to 'share this space' with tourists and, in some ways, the worst case scenario has been experienced whereby 'many of the Masai people have been exposed to the tourists without prior consent'. New relationships must therefore be formed which respect the Masai Mara people's traditions and culture as they are a vital part of the overall situation and, for many tourists, an integral part of the whole experience. However, controversy and conflict have characterized the development of tourism in the Masai Mara: 
This park was created against a background of decline in pastoral livelihoods and a shift towards a mixed economy, and controversy cropped up about the future relationship between wildlife, livestock and the Masai people in this part of the Masai land (Respondent 7).

In order for tourism to become sustainable, it is important to take account of the 'longstanding inequalities' which have dogged development, to encourage 'community involvement' and to ensure that the 'benefits of tourism are shared'.

There was general agreement among stakeholders that:

Tourism activity has greatly benefited the local culture and the environment. For instance, tourism has ... helped preserve some musical and dance traditions among the Masai, and also raised the level of environmental awareness to greater heights amongst the community living near this game reserve (Respondent 10).

However, while positive benefits may accrue through preservation of 'the Masai culture, language and religion', there are many negative impacts of tourism development:

Tourism has caused an undesirable impact on the Masai through them losing massive lands for the sake of creating considerable space and investment of the parks and reserves, also another contribution to the conflict by the fact that the local community exchanging their lifestyle from pastoralism to subsistence and commercial farming (Respondent 8).

There have been many issues arising from the historical practice of moving the Masai people to certain areas of the reserve, thus ignoring their historical rights to land. All stakeholders agree that the issue of land sharing is one of the root problems and many attribute the failings to 'a lack of financial resources', ' a lack of sufficient support from the Ministry of Tourism and Wildlife' and 'policy failures'. Policies which have been put in place have not been implemented; most notably the policy stating that locals should receive $19 \%$ of the revenue from tourism. This failure has led to resentment among the Masai people, who feel they are the victims of circumstances and that their resources have been unjustifiably depleted. This was succinctly expressed by one Masai village elder:

We did not fault in any way for us to be robbed of our land.

(Respondent 6).

The respondent went on to express concern that the Masais' whole history and culture are under threat:

They can longer say that they are typical Masais, since they have really changed culture-wise and lost too much of their best pasture lands to the local and national governments, who just by taking unfair advantage of their ignorance have put them at a risk of their only socioeconomic livelihood and ended their nomadic pastoralism (Respondent 6).

All stakeholders agreed that the fundamental problem facing the Masai people is that they have lost much of their traditional grazing land without adequate 
compensation. They have not received their due revenue and perceive that the benefits of tourism income are diverted to tourism cartels.

\subsection{The tourism operators}

Tourism in the Masai Mara is economically vital to Kenya, hence the development of tourist facilities has continued to rise and the number of tourists has continued to grow. The beauty of the Masai Mara means that it is 'almost inevitable' that it will be targeted for large-scale tourism. Although tourism tends to bring employment, in the Masai Mara the rise in tourism has not led to employment benefits for the local people:

Most of the employees are of a better-education background and come from other parts of the country. Many of the investors are foreigners and that means whatever profits they plough, won't get back to the local economy (Respondent 10).

However, there is open acknowledgement of the mutual dependency between the tourism operators, the indigenous people and the wildlife. All have a vested interest in guarding against:

Damage by wildlife on human beings, crops and livestock; and on the other hand, the human-caused damage to wildlife through poaching and destroying their habitat (Respondent 9).

Obviously the tourism industry will not be sustained unless the natural resources and the communities are preserved, and concerns were expressed:

In general the park is gradually deteriorating as well as being mismanaged due to the existence of mass tourism ... and the fact that the management is reluctant to limit the growth of tourism into the park. Indeed, there are ineffective controls for sustainability and a lack of thorough examination of the environmental impacts of tourism (Respondent 10).

Issues of 'recycling', 'the discharge of various pollutants' and 'waste management' were raised by many stakeholders and concerns were vehemently expressed:

Firstly I would mention about pollution which is caused by human refuse, both from the local communities and the tourists. There is also the issue of dumping especially plastic bags, leaking camera batteries, glass and metal litter in the bushes or thrown in open pits which not only causes a danger to scavenging wildlife but also pollutes the environment. For example, the dumping of the sewage material away from the tourist accommodation which is allowed to flow onto neighbouring grazing grounds and Masai settlements areas, or simply throwing the sewage materials from these campsites into the river from which wildlife, livestock and local communities draw their drinking water from (Respondent 10).

However, as tourists are paying customers, they tend to be provided with the facilities they want. One way to help conservation would be to limit their numbers, which the Government is reluctant to do. 


\subsection{The Kenyan government}

Across the world, there is much government rhetoric in favour of sustainable tourism development, however, to make this a reality for the Masai Mara requires the Kenyan government to build local infrastructure to protect both the economy and the wildlife, to retain the attractiveness of the tourist destination and to achieve a balance in stakeholder interests. From the stakeholder interviews, it was evident that the government has not played an effective role in ensuring a proper balance amongst stakeholders' interests. Criticism was voiced from all perspectives: 'I blame the government'; 'the government is responsible'; 'the government has failed'. Indeed, the government has also been accused of being the cause of issues and conflicts between stakeholders:

The government, despite having failed in several discussions about developing institutional capacity and extra efforts to discuss other related issues, still continue to lack the capacity to govern the reserve with any interdisciplinary cohesion, and as long as this continues it will remain hard to strike a balance between the rival claims of biodiversity, economic and social development. (Respondent 2).

The most fundamental issue identified was that of land, its usage and the income derived from it. The government was accused of not recognizing the significance of the land issue:

For us, the Masais, land is the cornerstone of our cultural reproduction (Respondent 6).

and it was widely acknowledged that the unequal distribution of revenue was a deep-rooted issue:

There has been inconsistency when it comes to payments to the Masais and at times they have ceased altogether from making the payments. If at all the local government really functioned, the best they could do is giving little money or services, to the Masai who lost land to the reserves and parks (Respondent 3 ).

Responsibility for the divisions raised by controversy over tourist income and the revenue returned to local people is attributed entirely to the governmental failures:

The lack of even minimal reinvestment, lack of transparency in the park revenue, cultural insensitivity, and the paternalistic conservation mentality of segregation have all played their part (Respondent 2).

This inconsistency in making payments, in turn, has led to feelings of insecurity about future finances, which in turn has led to a rise in poaching and other illegal activities as the Masai people not only try to make a living but also react to the 'paternalism' of governmental approaches.

Thus, stakeholders laid most of the blame for the current conflict-ridden situation at the feet of government. Their failures included lacking the capacity to govern the reserve with any interdisciplinary cohesion; a lack of even minimal reinvestment; mismanagement of land usage; a reluctance to limit the growth of 
tourism; and a lack of transparency in dispersing park revenue. Some stakeholders argued that because there is no accounting transparency there is suspicion that the money set aside for development projects to benefit the Masai people is being funnelled to projects benefiting the politically powerful and the tourism operators:

Most of this money goes directly to the private business sectors such as the tour operators, luxury lodges, transporters and while the rest goes straight to the central government treasuries (Respondent 7).

Such suspicions do nothing to heal stakeholder differences.

\section{Conclusions}

There was consensus among stakeholders that the way forward is to work together for the mutual benefit of the environment, the wildlife and all the people involved:

Continuously working closely with the local community through informing and consulting and engaging them with not only financial benefits but also with local development projects where the local people can help themselves and their families (Respondent 10).

There was much sympathy for the plight of the Masai Mara people whose traditional ways of life had been dramatically changed with the introduction of tourism:

I suggest that they should also be consulted on tourism development, and rather than being ignored, they must be made to feel that they are partners in decision making. I think this kind of gesture plays a big role of empowering them (Respondent 1).

It was felt that an important consequence of greater involvement of local people in decision-making would be that:

They will come to find that wildlife is more valuable than crops or cattle, and they will eventually start protecting it themselves (Respondent 3).

There was also consensus among stakeholders about the urgent need for action to be taken to preserve Kenya's unique game reserve. This action should include putting an infrastructure in place to manage the development of tourism; dispersing tourism revenue in an equitable fashion and in line with government policy; putting procedures in place to manage energy conservation and waste management; and looking beyond the tourist market to ensure the sustainability not only of tourism, but also of this vital asset:

Despite tourism being the key economic activity in the Mara region, my piece of advice is that let us not rely too much on what tourism benefits us in this area. Otherwise over reliance might lead to the Mara region being susceptible to seasonal, economic fluctuations and also changes in tourist tastes. My thinking is let tourism be one of the several activities in the region that fit in with the traditional 
activities for example complementing it with agriculture rather than competing with it or causing its decline (Respondent 6).

Fundamentally, government action is what is primarily required and for all stakeholders there was agreement that this action was both 'urgent' and 'very important' so that the Masai Mara becomes a sustainable tourist destination.

\section{References}

[1] Brundtland, G. Our Common Future: The World Commission on Environment and Development, Oxford University Press: Oxford, 1987.

[2] Bhandari, M. Tourism Raised Problems in Masai Mara National Park Narok, Kenya, Association for Protection of Environment and Culture (APEC- Nepal), www.mtnforum.org/rs/ol/counter docdown.cfm?fID =432.pdf, 1999 .

[3] Huby, M. Social Policy and the Environment, Open University Press: London, 1998.

[4] MacDonald, M. and Azumi, E. Wildebeests and Wheat: Crafting a Land Policy in Kenya's Maasailand, Report prepared for the Government of Kenya, Ministry of Planning and National Development, 1993.

[5] MacKillop, A. Talking About the Environment, Wayland: London, 1973.

[6] Omondi, P. Wildlife-human Conflict in Kenya: Integrating Wildlife Conservation with Human Needs in the Masai Mara Region, Ann Arbor: Michigan, 1997.

[7] Pflanz, M. Masai Mara Tourist Ban, The Telegraph, 20, January 2007.

[8] Said, M.Y. Multiscale Perspectives of Species Richness in East Africa, Wageningen Dissertation Abstracts, Wageningen University, Netherlands, 2003.

[9] Strauss, A. \& Corbin, J. Basics of Qualitative Research: Techniques and Procedures for Developing Grounded Theory, Sage: London, 1998.

[10] UNEP (United Nations Environment Programme), Agenda 21, United Nations Department of Economic and Social Affairs, Division for Sustainable Development, available at http://www.un.org/esa/sustdev/ documents/agenda21/index.htm, 1992.

[11] Walpole, M.J. \& Leader-Williams, N. Masai Mara Tourism Reveals Partnership Benefits, Nature, Vol. 413, No. 6858, pp. 771, 2001. 